Regards sur l'économie allemande

Bulletin économique du CIRAC

$93 \mid 2009$

Varia

\title{
Syndicats : la confédération DGB fête ses 60 ans
}

\section{Isabelle Bourgeois}

\section{OpenEdition \\ Journals}

Édition électronique

URL : http://journals.openedition.org/rea/3911

DOI : 10.4000/rea.3911

ISBN : 978-2-8218-0882-9

ISSN : 1965-0787

Éditeur

CIRAC

Édition imprimée

Date de publication : 1 octobre 2009

Pagination : 35

ISSN : 1156-8992

Référence électronique

Isabelle Bourgeois, "Syndicats : la confédération DGB fête ses 60 ans », Regards sur l'économie allemande [En ligne], 93 | octobre 2009, mis en ligne le 01 octobre 2011, consulté le 15 septembre 2020. URL : http://journals.openedition.org/rea/3911

Ce document a été généré automatiquement le 15 septembre 2020.

(C) CIRAC 


\title{
Syndicats : la confédération DGB fête ses 60 ans
}

\author{
Isabelle Bourgeois
}

1 La Confédération des syndicats allemands : Deutscher Gewerkschaftsbund (DGB) a vu le jour en 1949 lors de son congrès constitutif (12-14 octobre), baptisé : «Parlement du travail» (Parlament der Arbeit). Elle rassemble alors 16 syndicats. Le mouvement syndical (ouest-)allemand se reconstruit sur des fondations jamais reniées depuis, et qui ont assuré jusqu'ici à la fois la cohésion des organisations syndicales et leur représentativité : une représentation unitaire des salariés, basée sur le principe de la neutralité confessionnelle et partisane, et une représentation au niveau de la branche. Le président fondateur du DGB, Hans Böckler, né en 1875, ancien membre du syndicat des métaux, député du SPD de 1928 à 1933, a joué un rôle central non seulement dans la renaissance des syndicats en zone d'occupation britannique après la guerre, mais aussi dans la négociation du compromis sur la cogestion sous le gouvernement Adenauer (CDU). La première loi sur la cogestion dans le secteur du charbon et de l'acier (Montanmitbestimmungsgesetz) entre en vigueur le 21 mai 1951; et le 11 octobre 1952 la Loi sur la Constitution interne de l'entreprise (Betriebsverfassungsgesetz) qui confère aux Conseils d'entreprise (Betriebsräte) des droits de codécision très étendus (voir REA 72/04).

2 Le modèle du syndicat unitaire de branche prévaut toujours en Allemagne, bien qu'il soit partiellement mis à mal par le processus de mutation des activités qui a brouillé le périmètre des branches et généré, surtout dans le tertiaire, des activités peu ou pas représentées car trop hétérogènes pour être considérées comme des branches. En réponse à ces évolutions s'était constitué en 2001 un nouveau syndicat unitaire des services : ver.di, conglomérat rassemblant en son sein plus de 1000 métiers. Mais la culture du syndicat d'industrie, telle que l'incarnent encore IG Metall ou IG BCE (chimie) lui est par nature étrangère, et ver.di ne parvient pas à endiguer la montée en puissance des organisations professionnelles ou catégorielles comme l'ont révélé récemment encore les conflits dans les chemins de fer ou les transports aériens. La libéralisation des anciens services publics a accéléré les bouleversements observés dans 
les relations sociales allemandes (voir REA 83/07). Aujourd'hui, le taux de syndicalisation est tombé à $17 \%$, la moitié du niveau qu'il atteignait encore dans les années 1980. Le DGB, qui fédère aujourd'hui 8 syndicats de branche, compte près de 6,4 millions d'adhérents dont la majeure partie est membre d'IG Metall (2,3 millions) et de ver.di (2,2 millions). Il n'en reste pas moins un acteur institutionnel reconnu dans la triade décisionnelle : gouvernement/ patronat/mouvement syndical. (IB)

INDEX

Mots-clés : syndicat, DGB, Deutscher Gewerkschaftsbund, salarié, entreprise 